\title{
Extracellular vesicle-derived AEBP1 mRNA as a novel candidate biomarker for diabetic kidney disease
}

Yiying Tao', Xing Wei ${ }^{2}$, Yue Yue ${ }^{1}$, Jiaxin Wang ${ }^{1}$, Jianzhong Li ${ }^{1}$, Lei Shen ${ }^{1}$, Guoyuan Lu' ${ }^{1}$, Yang He ${ }^{3,5,6,7}$, Shidi Zhao', Fan Zhao ${ }^{1}$, Zhen Weng ${ }^{3,4,5,7}$, Xiahong Shen ${ }^{1 *}$ and Ling Zhou ${ }^{1 *}$

\begin{abstract}
Background: A novel and improved methodology is still required for the diagnosis of diabetic kidney disease (DKD). The aim of the present study was to identify novel biomarkers using extracellular vesicle (EV)-derived mRNA based on kidney tissue microarray data.

Methods: Candidate genes were identified by intersecting the differentially expressed genes (DEGs) and eGFRcorrelated genes using the GEO datasets GSE30528 and GSE96804, followed by clinical parameter correlation and diagnostic efficacy assessment.
\end{abstract}

Results: Fifteen intersecting genes, including 8 positively correlated genes, B3GALT2, CDH10, MIR3916, NELL1, OCLM, PRKAR2B, TREM1 and USP46, and 7 negatively correlated genes, AEBP1, CDH6, HSD17B2, LUM, MS4A4A, PTN and RASSF9, were confirmed. The expression level assessment results revealed significantly increased levels of AEBP1 in DKD-derived EVs compared to those in T2DM and control EVs. Correlation analysis revealed that AEBP1 levels were positively correlated with $\mathrm{Cr}$, 24-h urine protein and serum CYC and negatively correlated with eGFR and LDL, and good diagnostic efficacy for DKD was also found using AEBP1 levels to differentiate DKD patients from T2DM patients or controls.

Conclusions: Our results confirmed that the AEBP1 level from plasma EVs could differentiate DKD patients from T2DM patients and control subjects and was a good indication of the function of multiple critical clinical parameters. The AEBP1 level of EVs may serve as a novel and efficacious biomarker for DKD diagnosis.

Keywords: Diabetic kidney disease, Gene expression profiling, Plasma-derived extracellular vesicles, Adipocyte enhancer binding protein 1

\section{Background}

Diabetic kidney disease (DKD) is one of the most common and severe microvascular complications and is considered one of the most important causes of morbidity and mortality in diabetes patients, accounting for $40 \%$ of end-stage kidney disease cases [1, 2]. With

*Correspondence: njsxh87@163.com; zl66060@163.com

1 Department of Nephrology, The First Affiliated Hospital of Soochow University, Suzhou 215006, China

Full list of author information is available at the end of the article a high diabetes prevalence of up to 382 million worldwide, the number of DKD patients is expected to reach a historic high [3]. Therefore, it is necessary to explore the mechanisms involved in the process of DKD development, thereby shedding light on how to better control and prevent this kind of disease. According to the literature [4-6], multiple mechanisms have been reported to be involved in the pathophysiology of DKD, including inflammation, oxidative stress, mesangial hyperplasia and hemodynamics. However, due to the original author(s) and the source, provide a link to the Creative Commons licence, and indicate if changes were made. The images or other third party material in this article are included in the article's Creative Commons licence, unless indicated otherwise in a credit line to the material. If material is not included in the article's Creative Commons licence and your intended use is not permitted by statutory regulation or exceeds the permitted use, you will need to obtain permission directly from the copyright holder. To view a copy of this licence, visit http://creativecommons.org/licenses/by/4.0/. The Creative Commons Public Domain Dedication waiver (http://creativeco mmons.org/publicdomain/zero/1.0/) applies to the data made available in this article, unless otherwise stated in a credit line to the data. 
invasive nature of renal biopsy [7] and overestimation of the effectiveness of microalbuminuria quantification $[8,9]$, a novel and improved methodology is still required for the diagnosis of DKD.

Extracellular vesicles (EVs), including exosomes, microvesicles and other extracellular vesicles, can be secreted by multiple types of cells under normal and disease conditions with a specific average size of approximately 50-200 $\mathrm{nm}[10,11]$, and recent studies have shown that EVs could play important roles in intercellular communication signaling via several of their contents, including mRNAs, noncoding RNAs (miRNAs and long noncoding RNA) and proteins [12, 13]. Studies have shown that urinary EVs and bloodderived EVs could serve as biomarkers for DKD with the features of noninvasiveness and easy collection [14-16]; therefore, which type of EV-derived content is the most effective for diagnosing or monitoring a disease condition is worthy of exploration. Since quantitative reverse transcription polymerase chain reaction (RT-PCR) has been carried out for mRNA level evaluation in most biolabs in current practice, we tried to explore possible EV-derived mRNA biomarkers using plasma samples.

In the present study, we performed bioinformatics analysis to identify eGFR-correlated differentially expressed genes (DEGs) via previously published microarray datasets and validated the efficacy of selected genes in a cohort of DKD patients using plasma-derived EVs to provide a novel biomarker for DKD diagnosis.

\section{Methods}

\section{Patient inclusion and clinical data collection}

A total of 15 DKD patients and 10 healthy control volunteers were recruited from the Department of Nephrology, the First Affiliated Hospital of Soochow University, for plasma sample preparation from May 2019 to August 2020. The National Kidney Foundation Kidney Disease Outcomes Quality Initiative (NKF-KDOQI) guidelines [17] and the Consensus for Prevention and Treatment of Diabetic Kidney Disease 2014 of Chinese Diabetes Society [18] were employed as the diagnostic criteria for DKD patients, and guidelines published in 2010 by the American Diabetes Association (ADA) were used for type 2 diabetes mellitus [19], whereas patients suffering from autoimmune, infectious, hematological, malignant, organic or inflammatory diseases; who underwent renal replacement therapy; who were morbidly obese with body mass index $[\mathrm{BMI}] \geq 40 \mathrm{~kg} / \mathrm{m}^{2}$; or who had cardiovascular diseases accompanying severe complications were excluded. Clinical data were collected from all the patients, and detailed information is shown in Table 1.

\section{Acquisition of microarray data and related clinical data}

The mRNA expression and related experimental and clinical data of DKD were downloaded from Gene Expression Omnibus (GEO) (http://www.ncbi.nlm.nih.gov/geo/) using the search terms "diabetic kidney disease", "diabetic nephropathy" and "expression profiling by array". The gene expression microarray datasets GSE30528, GSE30529, GSE33744 and GSE96804 were selected and downloaded. The criteria for dataset selection were as follows: human clinical samples with detailed clinical and gene expression information or a mouse model with gene expression information. Among these datasets, GSE96804 was used for differentially expressed gene (DEG) screening, and GSE30528 combined with patient eGFR data downloaded from https://www.nephroseq. org/resource/login.html was used for correlated gene screening. GSE30528, GSE30529 and GSE33744 were used for expression-level validation of the 15 identified eGFR-correlated genes at different tissue composition and experimental mouse model levels. Detailed information on these microarray datasets is listed in Additional file 1: Table S1.

\section{Candidate gene identification and pathway analysis}

GSE96804, with 41 DKD kidney tissue samples and 20 control samples, was used for DEG screening, and the downloaded CEL data were processed with the R package affy [20] for background adjustment, quantile normalization, and median polish summarization, thereby obtaining the gene expression matrix. After performing the gene symbol annotation step using $\mathrm{R}$ package hgu133a2.db, the DEGs between DKD and control samples were identified by using $R$ package limma [21] (version 3.40.6) and criteria of fold change $>1.5$ and adjusted p-values $<0.05$. GSE30528, with gene expression data from DKD-derived kidney tissue and eGFR data, was used for eGFR-correlated gene screening with the Pearson correlation method. Moreover, a Venn diagram was used to determine the intersecting genes from the above DEGs and eGFR-correlated genes, followed by related expression level pattern validation using the data from GSE30528, GSE30529 and GSE33744. The flowchart of the data processing procedures is shown in Additional file 2: Fig. S1. In addition, the R package pheatmap [22] (version 1.0.12) was employed for heatmap and volcano map preparation for DEGs from GSE96804, whereas the R package clusterProfiler [23] (version 3.14.3) was used for Gene Ontology and KEGG pathway analysis for DEGs and eGFR-correlated genes. The present study was approved by the Ethics Committee of the First Affiliated Hospital of Soochow University and was carried out in accordance with the Declaration of 
Table 1 Clinical characteristics of the included subjects

\begin{tabular}{|c|c|c|c|c|}
\hline Clinical parameters & Control $(n=10)$ & T2DM $(n=15)$ & $\mathrm{DKD}(\mathrm{n}=15)$ & P-value \\
\hline Age (yrs) & $47.10 \pm 9.27$ & $48.00 \pm 10.95$ & $60.13 \pm 11.76$ & 0.0048 \\
\hline Gender (female, \%) & $3(30.00 \%)$ & $4(26.67 \%)$ & $2(13.33 \%)$ & 0.5585 \\
\hline BMI & $23.75 \pm 3.54$ & $26.33 \pm 5.77$ & $24.80 \pm 2.16$ & 0.3081 \\
\hline $\mathrm{SBP}(\mathrm{mmHg})$ & $127.10 \pm 16.96$ & $123.07 \pm 10.07$ & $155.50 \pm 20.18$ & $<0.0001$ \\
\hline $\mathrm{DBP}(\mathrm{mmHg})$ & $82.50(78.75-85.50)$ & $81.00(76.00-85.00)$ & $85.00(81.00-90.00)$ & 0.4273 \\
\hline T2DM duration (yrs) & - & $2(0.25-8)$ & $10(10-20)$ & $<0.0001$ \\
\hline HbA1c (\%) & - & $10.32 \pm 2.24$ & $7.34 \pm 1.26$ & $<0.0001$ \\
\hline eGFR (MDRD, $\left.\mathrm{ml} / \mathrm{min} / 1.73 \mathrm{~m}^{2}\right)$ & $133.95 \pm 32.80$ & $143.73 \pm 30.72$ & $18.59 \pm 12.64$ & $<0.0001$ \\
\hline eGFR (CKD-EPI, ml/min/1.73m²) & $107.19 \pm 16.53$ & $116.34 \pm 13.32$ & $18.05 \pm 12.87$ & $<0.0001$ \\
\hline BUN (mmol/L) & $4.75 \pm 1.10$ & $5.20 \pm 1.89$ & $19.17 \pm 10.53$ & $<0.0001$ \\
\hline Creatinine $(\mu \mathrm{mol} / \mathrm{L})$ & $57.83 \pm 11.96$ & $55.70 \pm 11.48$ & $465.72 \pm 342.07$ & $<0.0001$ \\
\hline $\mathrm{TC}(\mathrm{mmol} / \mathrm{L})$ & $4.71 \pm 0.87$ & $4.72 \pm 0.83$ & $4.85 \pm 1.82$ & 0.9483 \\
\hline TG (mmol) & $0.85(0.54-2.34)$ & $1.77(1.57-3.02)$ & $1.49(1.27-2.95)$ & 0.0791 \\
\hline $\mathrm{LDL}(\mathrm{mmol} / \mathrm{L})$ & - & $2.62 \pm 0.84$ & $2.55 \pm 1.33$ & 0.8668 \\
\hline $\mathrm{HDL}(\mathrm{mmol} / \mathrm{L})$ & - & $0.93 \pm 0.27$ & $0.91 \pm 0.17$ & 0.8344 \\
\hline 24-h urine protein $(\mathrm{g} / \mathrm{d})$ & - & - & $6.92 \pm 3.10$ & - \\
\hline Urine protein to creatinine ratio & - & $0.06 \pm 0.04$ & $4.87 \pm 2.03$ & $<0.0001$ \\
\hline Albumin (g/L) & $43.47 \pm 1.81$ & $40.42 \pm 3.10$ & $30.37 \pm 6.26$ & $<0.0001$ \\
\hline Albumin/creatinine ratio $(\mathrm{mg} / \mathrm{g})$ & $3.44(0.22-6.49)$ & - & $2692.30(1251.19-4346.50)$ & $<0.0001$ \\
\hline Urine $\beta 2 M G$ (mg/L) & $0.21(0.04-0.27)$ & - & $20.83(12.07-31.28)$ & $<0.0001$ \\
\hline Urine RBP (mg/L) & $0.15(0.01-0.42)$ & - & $13.40(7.80-18.54)$ & $<0.0001$ \\
\hline Urine CYC (mg/L) & $0.01(0.01-0.11)$ & - & $1.58(0.82-2.21)$ & $<0.0001$ \\
\hline Serum CYC (mg/L) & - & $0.78 \pm 0.07$ & $3.64 \pm 1.71$ & $<0.0001$ \\
\hline Hemoglobin (g/L) & $137.20 \pm 8.64$ & $141.47 \pm 13.63$ & $94.40 \pm 17.76$ & $<0.0001$ \\
\hline WBC $\left(10^{9} / L\right)$ & $6.15 \pm 1.06$ & $6.23 \pm 1.04$ & $6.10 \pm 1.87$ & 0.9712 \\
\hline Monocytes $\left(10^{9} / \mathrm{L}\right)$ & $0.43 \pm 0.07$ & $0.45 \pm 0.13$ & $0.51 \pm 0.28$ & 0.5720 \\
\hline Lymphocytes $\left(10^{9} / \mathrm{L}\right)$ & $2.11 \pm 0.59$ & $2.12 \pm 0.47$ & $1.45 \pm 1.20$ & 0.0685 \\
\hline Neutrophils $\left(10^{9} / \mathrm{L}\right)$ & $3.45 \pm 0.98$ & $3.50 \pm 1.03$ & $4.12 \pm 1.45$ & 0.2756 \\
\hline hsCRP (mg/L) & - & $1.51(1.13-2.88)$ & $1.92(0.61-3.18)$ & 0.9907 \\
\hline
\end{tabular}

Measurement data was expressed as mean \pm standard deviation (SD) or median and interquartile range according to normal distribution statue, categorial data was expressed as number and percentages

$B M I$ body mass index, SBP systolic blood pressure, DBP diastolic blood pressure, T2DM type Il diabetes mellitus, HbA1C glycated hemoglobin, MDRD The Modification of Diet in Renal Disease, CKD-EPIThe Chronic Kidney Disease Epidemiology Collaboration, $T C$ total cholesterol, $T G$ triglycerides, $H D L$ high density lipoprotein, $L D L$ lowdensity lipoprotein cholesterol, BUN blood urea nitrogen, RBP retinol-binding protein, CYC cystatin-C, WBC White Blood Cell

Helsinki. Written informed consent was provided by all the included subjects.

\section{EVs isolation and characterization}

Five milliliters of anticoagulant-treated venous blood was collected from the abovementioned DKD and control subjects for plasma isolation, and exosomes were isolated from whole blood with sequential centrifugation and an ExoQuick $^{\text {TM }}$ Plasma Prep and Exosome Precipitation Kit (Cat\# EXOQ5TM-1, SBI System Biosciences, Mountain View, CA, USA) according to the manufacturer's instructions. Briefly, sequential centrifugation at $1200 \mathrm{~g}$ for $10 \mathrm{~min}, 3000 \mathrm{~g}$ for $20 \mathrm{~min}$, and $10,000 \mathrm{~g}$ for $30 \mathrm{~min}$ was performed on the whole blood to remove the blood cells, dead cells and large vesicle to obtain the plasma supernatant, followed by mixing with ExoQuick Exosome Precipitation Solution at the ratio of 4:1 and sequential centrifugation at $1500 \mathrm{~g}$ for $30 \mathrm{~min}$ and $1500 \mathrm{for} 5 \mathrm{~min}$; then, the precipitated pellet containing exosomes was obtained and resuspended in $1 \times$ PBS for further study. EV characterization was carried out using electron microscopy for morphology observation, dynamic light scattering (DLS) for particle size distribution and western blotting for protein marker identification. For electron 
microscopy, exosomes resuspended in $2 \mu \mathrm{g} / \mathrm{ml}$ PBS were fixed with $2 \%$ paraformaldehyde (PFA) at a ratio of 1:1 and loaded onto transmission electron microscopy grids until dry, followed by $1 \%$ glutaraldehyde fixation, purified water washing and $1 \%$ phosphotungstic acid (PTA) staining. The samples were observed using a Tecnai G2 Spirit BioTwin transmission electron microscope (FEI company, Hillsboro, OR, USA). For DLS, exosomes resuspended in $2 \mu \mathrm{g} / \mathrm{ml}$ PBS were diluted with PBS at a ratio of 1:1000 and then subjected to NanoSight LM10 (Malvern Panalytical, UK) for analysis. For western blotting, exosomes and exosome-depleted supernatant (EDS; negative control) from DKD patients and control subjects were processed for analysis. Forty-five micrograms of exosomes and the same volume of EDS were loaded for SDS-PAGE, followed by PVDF membrane transfer, nonfat milk blocking, primary and secondary antibody incubation, and chemiluminescence exposure. The primary antibodies for Flotillin-1 and GM130 were obtained from Cell Signaling Technology (Cat. no: 74220), and antiCD63 was obtained from Abcam (Cat. no: ab252919).

\section{EV-derived RNA extraction and evaluation of gene expression levels}

RNA extraction from EVs was performed using TRIzol ${ }^{\mathrm{TM}}$ Reagent (Thermo Fisher, CA, USA) according to the manufacturer's instructions. After RNA quantification and qualification by a NanoDrop 2000 (Thermo Fisher, CA, USA), reverse transcription and quantitative PCR were carried out using a RevertAid RT Reverse Transcription Kit (Thermo Fisher, CA, USA) and SYBR Green qPCR Mix (Beyotime, Nantong, China), respectively, to evaluate the expression level of AEBP1. The expression of GAPDH was selected as the internal control according to previous publications $[24,25]$. The primer sequences were as follows: AEBP1: Forward: 5'ACCCACACTGGA CTACAATGA-3', Reverse: 5'-GTTGGGGATCACGTA ACCATC-3'; GAPDH: Forward: 5'-GCAAATTCCATG GCACCGT-3', Reverse: 5'-TCGCCCCACTTGATTTTG G-3'

\section{Statistical analysis}

Statistical analysis was carried out using $\mathrm{R}$ version 3.6.0. Measurement data are expressed as the mean \pm standard deviation (SD), and categorical data are expressed as numbers and percentages. One-way ANOVA and Kruskal-Wallis $\mathrm{H}$ tests for parametric and nonparametric continuous variables were used to compare three groups, while unpaired $t$ tests and Mann-Whitney $U$ tests for parametric and nonparametric continuous variables were used for 2-group comparisons. Correlation analysis between the clinical parameters and AEBP1 expression level was performed using Pearson correlation. The diagnostic efficacy was calculated by receiver operator characteristic (ROC) curves and area under the curve (AUC) (survivalROC and ROCR R packages). Unless specifically mentioned, $\mathrm{P}<0.05$ was considered statistically significant.

\section{Results \\ Identification of candidate genes and pathway analysis}

To identify candidate genes for further analysis in EVs, we first obtained DEGs from the GSE96804 dataset and constructed volcano plot (Fig. 1A), heatmap (Fig. 1B), GO pathway (Fig. 1C-E) and KEGG pathway (Fig. 1F) figures. A total of 577 DEGs were identified, including 251 upregulated genes and 326 downregulated genes. GO pathway analysis revealed small-molecule catabolic processes, leukocyte migration, cellular amino acid metabolic process as the top 3 biological processes (BPs) (Fig. 1C); collagen-containing extracellular matrix, apical part of cell and apical plasma membrane as the top 3 cellular components (CCs) (Fig. 1D); and extracellular matrix structural constituent, anion transmembrane transporter activity and organic anion transmembrane transporter activity as the top 3 molecular functions (MFs) (Fig. 1E). Protein digestion and absorption, drug metabolismcytochrome $\mathrm{p} 450$, and the PPAR signaling pathway were the top 3 KEGG pathways (Fig. 1F). eGFR-correlated genes (577 genes, including 370 positively correlated and 207 negatively correlated) were also calculated using the GSE30528 dataset and patient eGFR data, and the results are shown in Fig. 2A. Moreover, GO pathway analysis of the top 10 BPs, CCs and MFs (Fig. 2B-D) and the top 10 KEGG pathways (Fig. 2E) was also performed. Then, the 15 intersecting genes from eGFR-correlated genes and DEGs were confirmed (Fig. 3A), including 8 positively correlated genes, B3GALT2, CDH10, MIR3916, NELL1, OCLM, PRKAR2B, TREM1 and USP46, and 7 negatively correlated genes, AEBP1, CDH6, HSD17B2, LUM, MS4A4A, PTN and RASSF9. Moreover, the correlations between these 15 genes and eGFR were also explored (Fig. 3B, Table 2 and Additional file 1: Table S2).

\section{Identification of the expression pattern of 15 intersecting genes}

We further evaluated the expression pattern of 15 intersecting genes in 3 microarray datasets, GSE30528, GSE30529 and GSE33744. The up- and downregulated trends of the 15 intersecting genes in human DKD and control glomeruli samples from GSE30528, human DKD and control tubule samples from GSE30529, glomeruli samples from diabetic $\mathrm{BKS} \mathrm{db} / \mathrm{db}$ mice from 


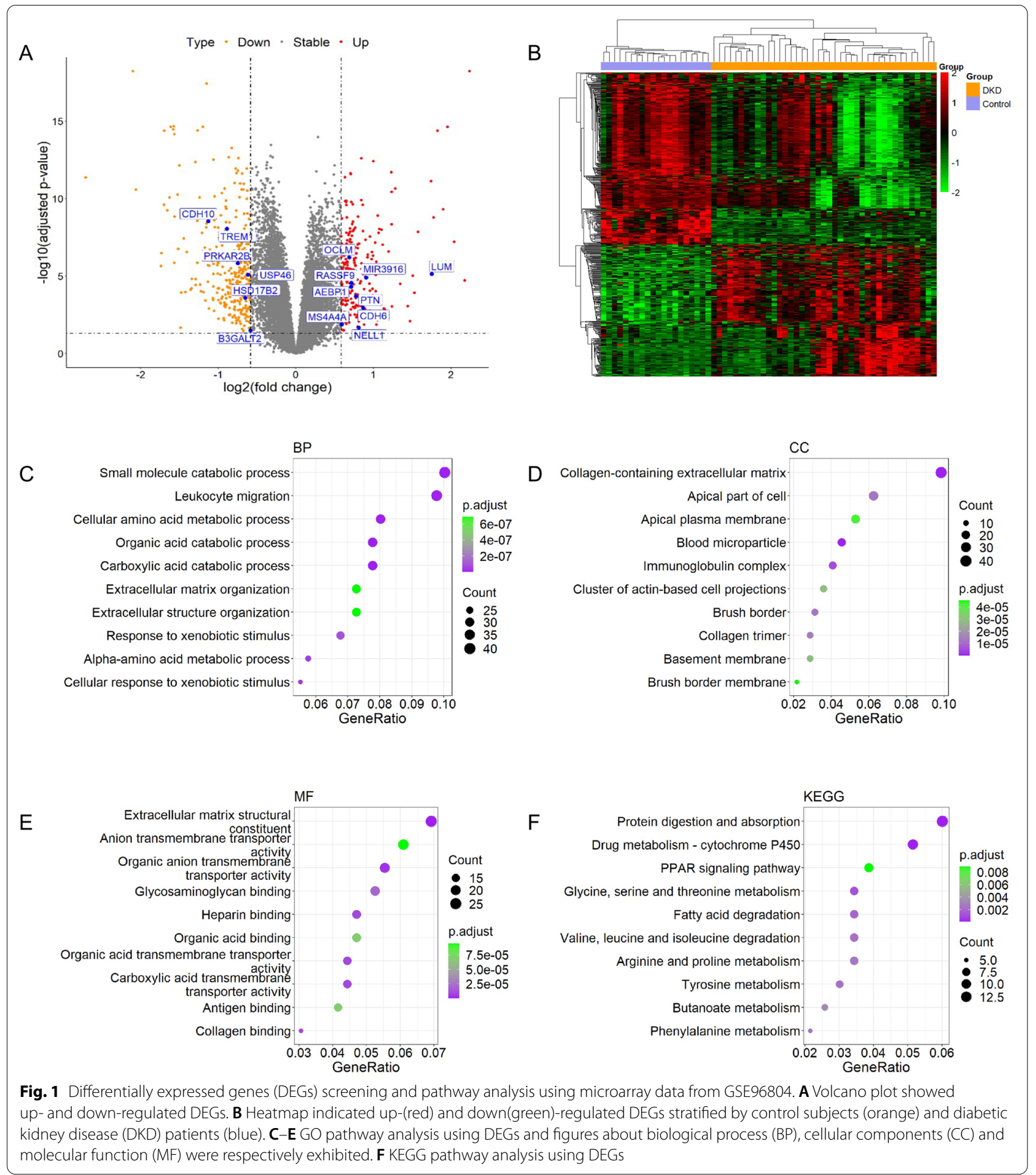

GSE33744, glomeruli samples from diabetic DBA-STZ mice from GSE33744 and glomeruli samples from diabetic BKS $\mathrm{db} / \mathrm{db}$ eNOS - / - mice from GSE33744 are shown in Fig. 4A-E and Table 3. Because of the consistent expression pattern of AEBP1 in 4 of the above human and mouse kidney-derived tissues, it was selected for further analysis. Moreover, considering filtration between blood and glomeruli in renal physiology, it is reasonable to use plasma-derived samples. 


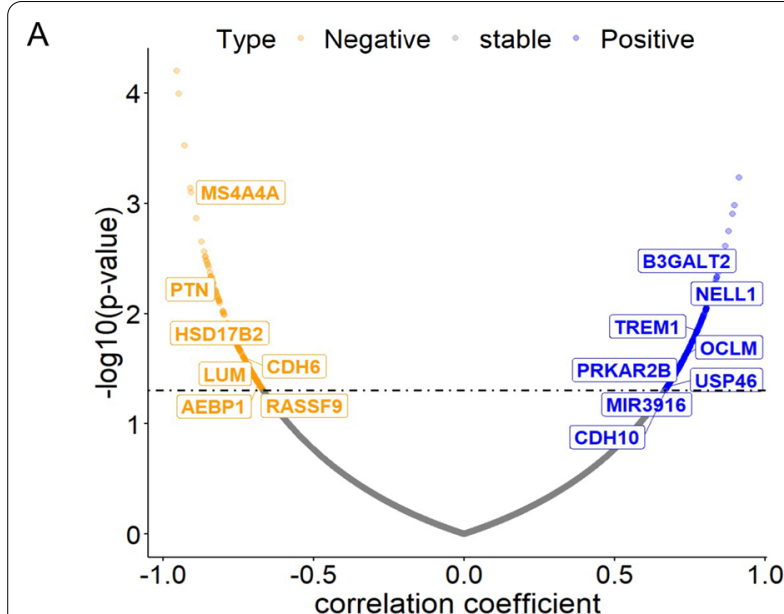

B

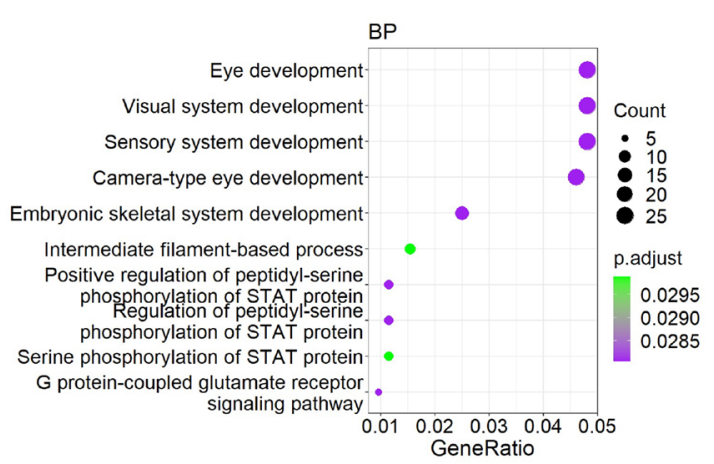

$\mathrm{D}$

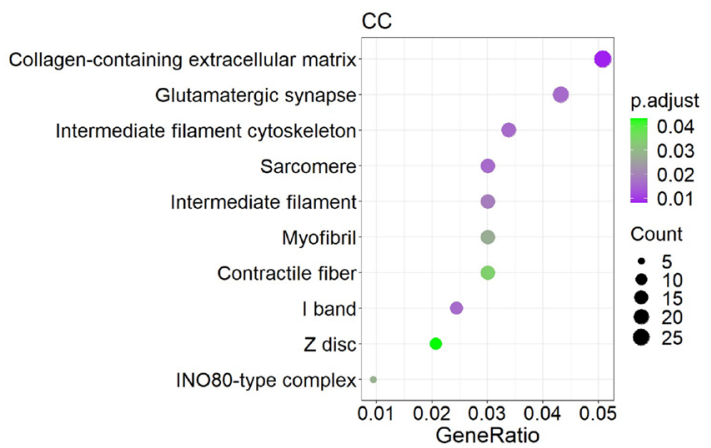

C

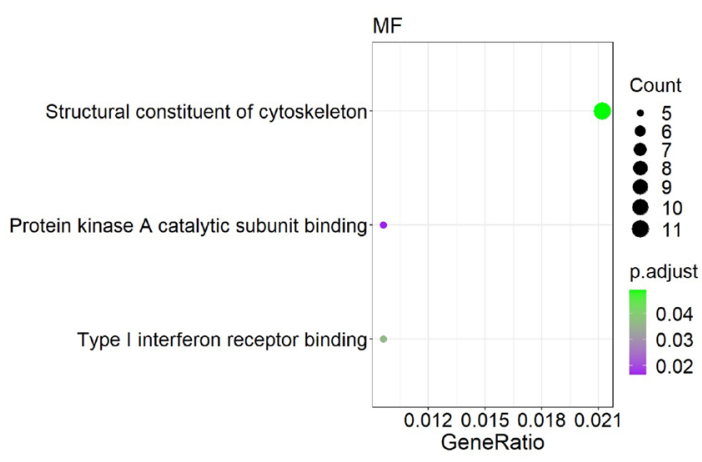

$\mathrm{E}$

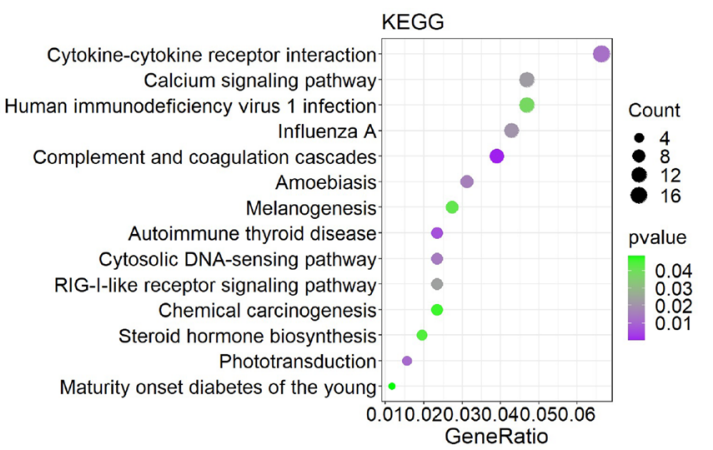

Fig. 2 eGFR correlated genes screening and pathway analysis using microarray data from GSE30528. A Pearson correlation was performed to obtain the eGFR correlated genes. B-D GO pathway analysis using eGFR correlated genes and figures about biological process (BP), cellular components (CC) and molecular function (MF) were respectively exhibited. E KEGG pathway analysis using eGFR correlated genes

\section{Characterization of EVs from DKD and T2DM patients and controls and evaluation of the expression level of AEBP1}

According to the electron microscopy (Fig. 5A), DLS (Fig. 5B) and western blotting results (Fig. 5C), we obtained round morphology exosomes with a mean size of $107 \mathrm{~nm}$ in control subjects, $128 \mathrm{~nm}$ in T2DM patients and $90 \mathrm{~nm}$ in DKD patients with positive expression of $\mathrm{CD} 9, \mathrm{CD} 63$ and $\mathrm{CD} 81$ and negative expression of GM130 and ApoB, which is consistent with previous reports $[10,11]$. We further evaluated the expression levels of AEBP1 using exosome RNA 


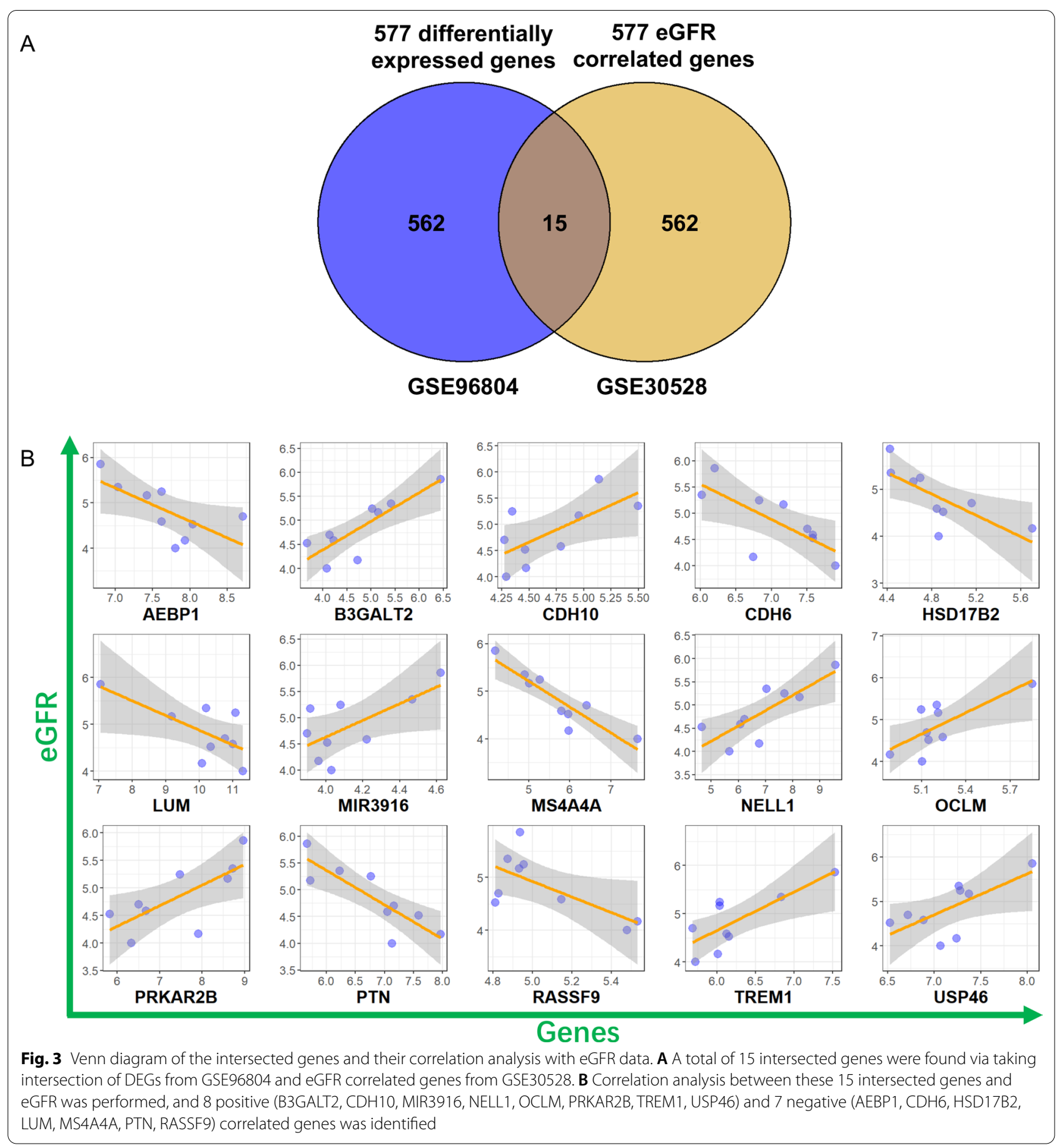

from DKD and control subjects, and significant AEBP1 expression was found in DKD patients compared to T2DM patients $(p=0.023$, Fig. $5 \mathrm{D})$ or control subjects $(p=0.0009$, Fig. 5D). These results suggested the possible involvement of AEBP1 in the disease process of DKD.
Correlation between the expression level of EV-derived AEBP1 and clinical indexes of DKD and exploration of the diagnostic efficacy of AEBP1

Since we observed the possible involvement of AEBP1 in the disease process of DKD, we evaluated the correlation between the expression level of EV-derived AEBP1 
Table 2 Correlation coefficient and gene function of 15 intersected genes

\begin{tabular}{lrl}
\hline Gene names & R value & P value \\
\hline AEBP1 & -0.68 & 0.042 \\
B3GALT2 & 0.83 & 0.0047 \\
CDH10 & 0.67 & 0.046 \\
CDH6 & -0.73 & 0.025 \\
HSD17B2 & -0.74 & 0.021 \\
LUM & -0.69 & 0.041 \\
MIR3916 & 0.67 & 0.047 \\
MS4A4A & -0.91 & 0.00079 \\
NELL1 & 0.80 & 0.0092 \\
OCLM & 0.73 & 0.023 \\
PRKAR2B & 0.72 & 0.028 \\
PTN & -0.84 & 0.0043 \\
RASSF9 & -0.67 & 0.049 \\
TREM1 & 0.77 & 0.014 \\
USP46 & 0.68 & 0.046 \\
\hline
\end{tabular}

and clinical parameters of DKD. The results showed that the expression level of EV-derived AEBP1 was positively correlated with $\mathrm{Cr}$, 24-h urine protein and serum CYC and negatively correlated with eGFR and LDL (Fig. 6) but not age, BMI, SBP, DBP, HbA1c (\%), BUN, TC, TGs, HDL, plasma creatinine, albumin, albumin/creatinine ratio, urine $\beta 2 \mathrm{MG}$, urine $\mathrm{RBP}$, urine $\mathrm{CYC}$, hemoglobin, WBC, monocytes, lymphocytes or neutrophils (Table 4 and Additional file 3: Figure S2). Moreover, a trend of correlation could be found between AEBP1 level and hsCRP $(\mathrm{r}=0.474, \mathrm{p}=0.074)$ (Table 4 and Additional file 3: Figure S2). Furthermore, we had to point out that although a significant difference in age and SBP could be found between control and DKD patients, no correlation of these 2 indexes with the AEBP1 level could be found (Additional file 4: Figure S3). In addition, good diagnostic efficacy for DKD was also found using the expression level of exosome-derived AEBP1, with an AUC of 0.880 and $p<0.001$ for differentiating healthy controls and an AUC of 0.742 and $p=0.009$ for differentiating T2DM according to the ROC curve (Fig. 7). The optimal cutoff value for AEBP1 mRNA level was 0.511 (specificity: 0.800 , sensitivity: 0.867 ) and 0.403 (specificity: 0.533 , sensitivity: 0.867 ) for control vs. DKD and T2DM vs. DKD, respectively.

\section{Discussion}

EVs, secreted by almost all cell types, are nanoscale lipid bilayer spherical shapes containing various receptors, proteins, genetic materials (DNA, mRNA and miRNAs, etc.) with intercellular communication abilities that are made possible by three major mechanisms: receptor-ligand interactions, direct plasma membrane fusion and endocytosis [26, 27]. With the deep recognition of EVs, they have been discovered in multiple biological fluids, including blood, urine, saliva and cerebrospinal fluid, and because these sample types are common in clinical practice, the employment of EVs in disease diagnosis and assessment is reasonable [16, 28]. Eissa et al. reported the employment of urinary EVderived miR-15b, miR-34a, miR-636, miR-133b, miR-342 and miR-30a as biomarkers in type $2 \mathrm{DN}$ patients [29, 30]. Zubiri et al. suggested the use of urinary bikunin precursor and histone-lysine N-methylthransferase (KHMT) as biomarkers for DKD patients [31], whereas Rossi et al. [32] found that urinary EV-derived AQP2 and AQP5 could be used as biomarkers for DKD patients. Since the use of a single miRNA could only exhibit limited accuracy and specificity as a disease biomarker and the detection of enzyme activity, such as KHMT, is relatively expensive, the possible detection of specific EV-derived mRNA molecules could be a better choice. Furthermore, the vascular property of glomeruli and the adequate number of EVs derived in blood make it reasonable to explore possible novel biomarkers in plasma-derived exosomes.

In the present study, based on the shared microarray datasets in GEO and the available patient eGFR from Nephroseq v5, we first identified eGFR-correlated DEGs from human glomeruli samples, verified these genes in multiple human and mouse models, and then identified AEBP1 as a novel and effective candidate gene for further experiments. Due to the easy collection of blood samples without renal biopsy and the maturity of the methodology of EV isolation, we checked the expression of AEBP1 using EV-derived RNA, and the results showed a significant increase in AEBP1 expression in DKD patients compared to that in control subjects. Moreover, we found that AEBP1 levels were negatively correlated with eGFR and LDL and positively correlated with $\mathrm{Cr}$, 24-h urine protein, and serum CYC. In addition, good diagnostic efficacy could be achieved using EV-derived AEBP1 levels with an AUC of 0.880 . This is the first report of EV-derived AEBP1 levels as a novel biomarker for DKD diagnosis.

The advantages of plasma vesicle mRNA markers are as follows: Since the changes in renal pathology occur earlier than reflected by the existing indexes, such as eGFR and urinary albumin, the plasma vesicle mRNA could be an early marker of pathology. Urinary samples could be affected by multiple factors, including drinking water, food consumption and urinary tract infection. Plasmaderived EVs are stable and adequate and could reflect versatile cell type derivates. 


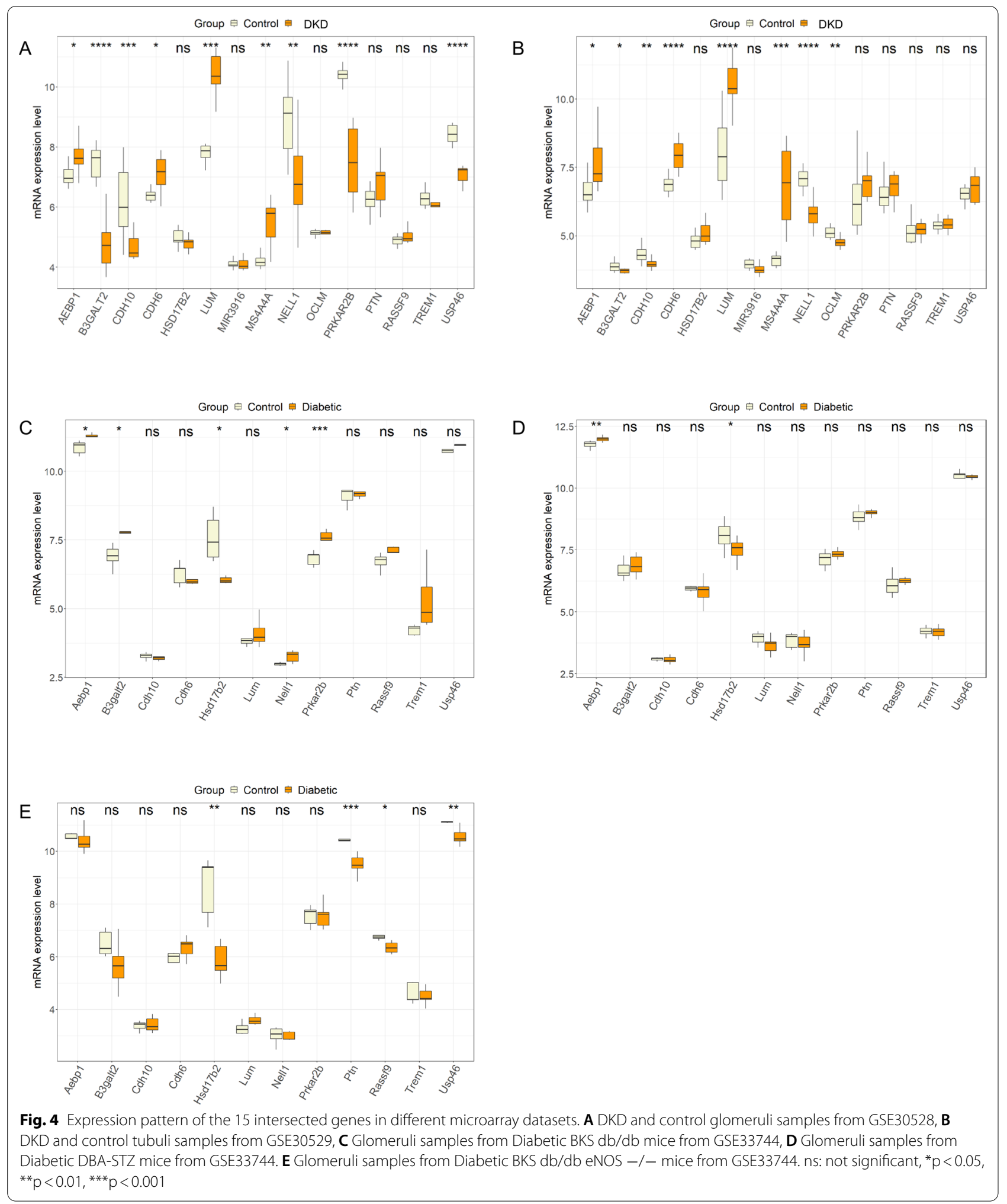


Table 3 Significantly up and down-regulated genes in different microarray datasets among the 15 intersected genes

\begin{tabular}{llll}
\hline Microarray set no. & Sample type & Up & Down \\
\hline GSE30528 & Human DKD and control glomeruli samples & AEBP1, CDH6, LUM, MS4A4A & B3GALT2, CDH10, NELL1, PRKAR2B, USP46 \\
GSE30529 & Human DKD and control tubuli samples & AEBP1, CDH6, LUM, MS4A4A, PRKAR2B B3GALT2, CDH10, NELL1, OCLM \\
GSE33744 & $\begin{array}{l}\text { Glomeruli samples from Diabetic BKS db/db } \\
\text { mice }\end{array}$ & AEBP1, B3GALT2, NELL1, PRKAR2B & HSD17B2 \\
GSE33744 & $\begin{array}{l}\text { Glomeruli samples from Diabetic DBA-STZ } \\
\text { mice }\end{array}$ & AEBP1 & HSD17B2 \\
GSE33744 & $\begin{array}{l}\text { Glomeruli samples from Diabetic BKS db/db } \\
\text { eNOS -/- mice }\end{array}$ & HSD17B2, PTN, RASSF9, USP46 \\
\end{tabular}

Adipocyte enhancer binding protein 1 (AEBP1) was first found in adipocytes and has been reported to be involved in multiple biological processes, including cell differentiation [33], adipogenesis [34], cholesterol homeostasis and inflammation [35]. In the correlation analysis, we found a correlation between AEBP1 and LDL levels and a trend of correlation between AEBP1 levels and hsCRP in DKD patients, which is consistent with the above-stated role of AEBP1 in cholesterol homeostasis and inflammation [35]. Moreover, AEBP1 was reported to be expressed in macrophages with inflammatory-enhancing effects $[35,36]$. However, we did not find a correlation between AEBP1 levels and WBCs, monocytes, lymphocytes or neutrophils, which further strengthens the role of AEBP1 in inflammatory cell differentiation but not in cell number increase. Furthermore, AEBP1 is also considered to be involved in multiple disease and pathological processes, and increased levels of AEBP1 accompanying several signal pathway dysfunctions (such as NF- $\mathrm{KB}$ [37], Hedgehog [38], etc.) could be found in liver fibrosis [39], Alzheimer's disease [40], breast epithelial cell hyperproliferation [38], abdominal aortic aneurysm [37] and colorectal cancers [41]. In addition, AEBP1 mutation could also result in hereditary connective tissue diseases [42]. Here, we detected AEBP1 mRNA in plasma-derived exosomal RNA and confirmed its upregulated pattern in DKD patients. According to previous studies, upregulated AEBP1 could be regulated by the transcription factor CREB and the PI3K/ Akt pathway in melanoma cells [43], and activation of the PI3K/Akt signaling cascade could be found in diabetic patient-derived peripheral blood mononuclear cells (PBMCs) [44]. Therefore, these PBMCs could be the possible origin of the AEBP1-containing exosomes. In addition, considering the inflammatory state of the kidney and the expression of AEBP1 in glomerular tissues, upregulation of AEBP1 levels in plasma could also result from kidney-derived cells, which is consistent with the microarray results showing upregulation of AEBP1 levels in glomerular tissues.

In addition to AEBP1, we also found 14 other eGFRcorrelated genes here, most of which lack functional studies with only microarray information. According to previous studies, B3GALT2 was previously shown to be downregulated in a mouse model of diabetic nephropathy [45], and CDH6 was upregulated in renal fibrosis mice [46]. Upregulated HSD17B2 and LUM were found in diabetic $\mathrm{db} / \mathrm{db}$ mice [47] and human-derived kidney tissues, respectively [48]. NELL1 is a target antigen in malignancy-associated membranous nephropathy [49]. PTN triggers inflammation and increases peritoneal permeability, leading to peritoneal fibrosis [50]. TREM-1 plays an important role in high-glucoseinduced macrophage phenotypic transformation during the progression of DKD [51], whereas no report has been found on the CDH10, MIR3916, MS4A4A, OCLM, RASSF9 or USP46 genes in DKD.

There are several limitations in present study. First, the relatively small number of DKD patients could result in bias in the results on the diagnostic efficacy and difference comparison between the patients and normal subjects. Second, the difficulties that were faced in the recruitment of diabetes patients in our department could result in an inability to determine the AEBP1 level in these patients. Third, due to the lack of basic cell or animal models, the detailed mechanisms by which exosomes with high AEBP1 expression are involved in the disease process of DKD have not been fully explored. Therefore, further study with a larger number and more complete types of patients could be helpful for testing the results obtained here. In addition, a mechanistic study of AEBP1 might also be performed to elucidate its possible role in DKD. 

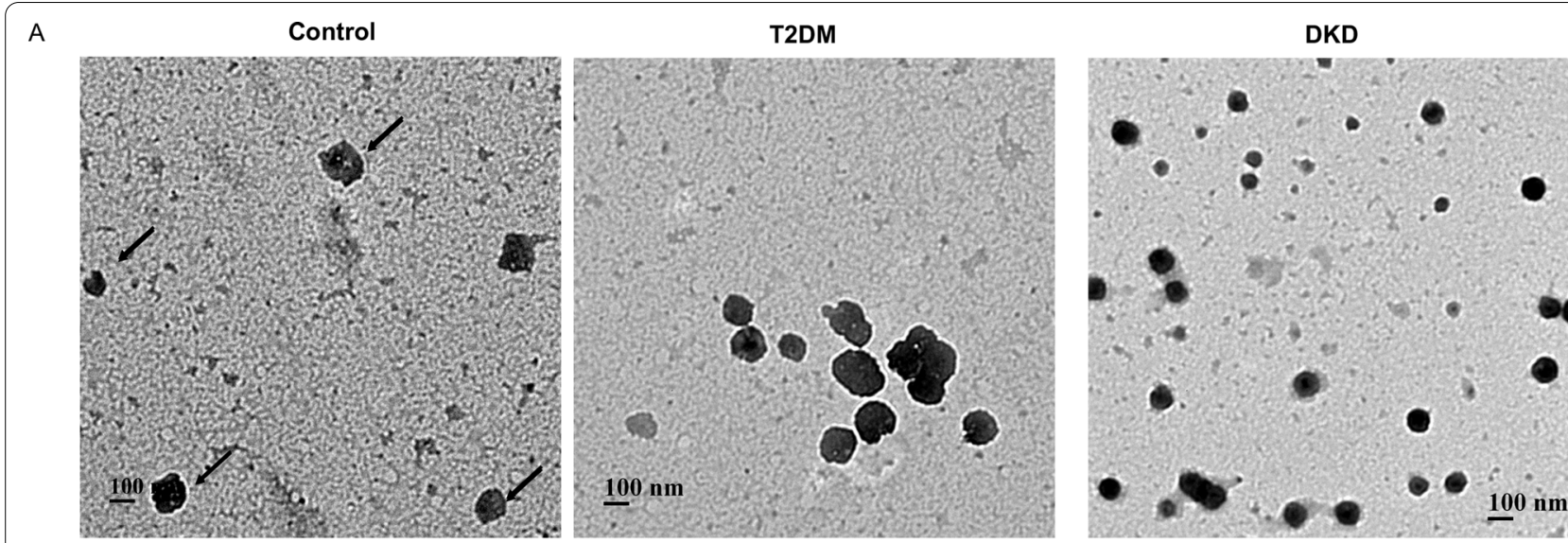

B

Control

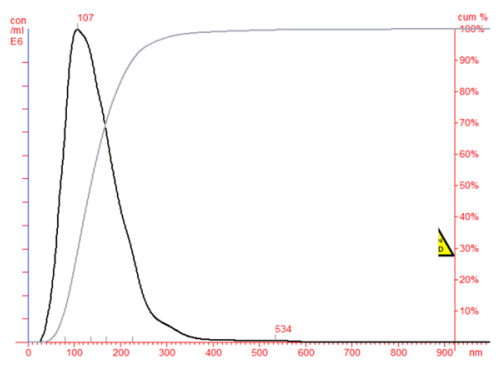

Particle Size / Concentration

C

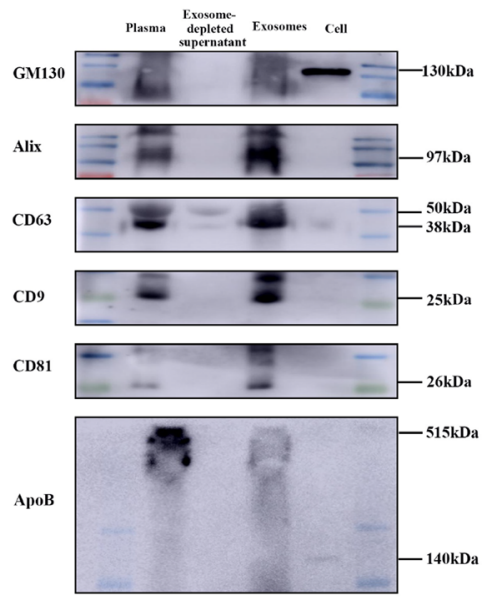

T2DM

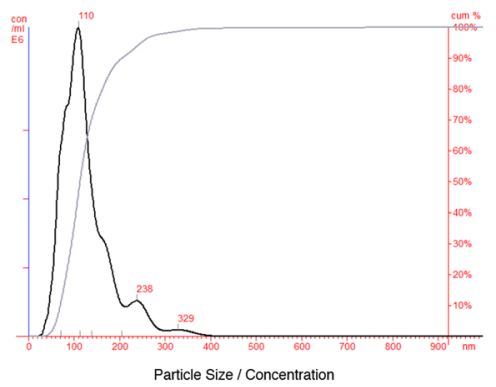

D
DKD

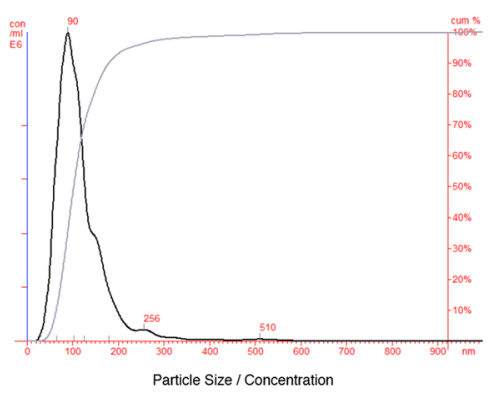

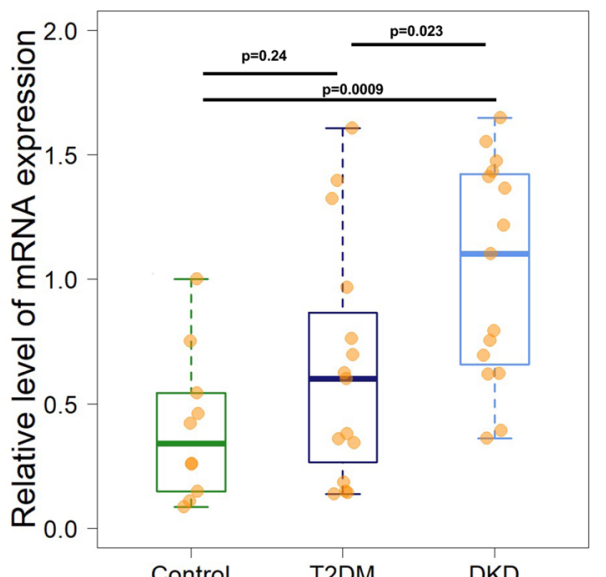

Fig. 5 Characterization of extracellular vesicle (EV) from DKD patients, T2DM patients and control subjects and evaluation of the expression level of AEBP1. A Representative electronic microscope photograph of EVs from control (with arrow head) subject, T2DM patient (black stained) and DKD patient (black stained). B Dynamic light scattering (DLS) results for exosome particles distribution from control subject, T2DM patient and DKD patient. C Western-blotting results for exosome marker evaluation in control, T2DM and DKD derived exosomes, whereas PBS as negative control. D Significantly increased level of AEBP1 mRNA could be found in DKD patient derived exosome compared to T2DM patient and control subjects 

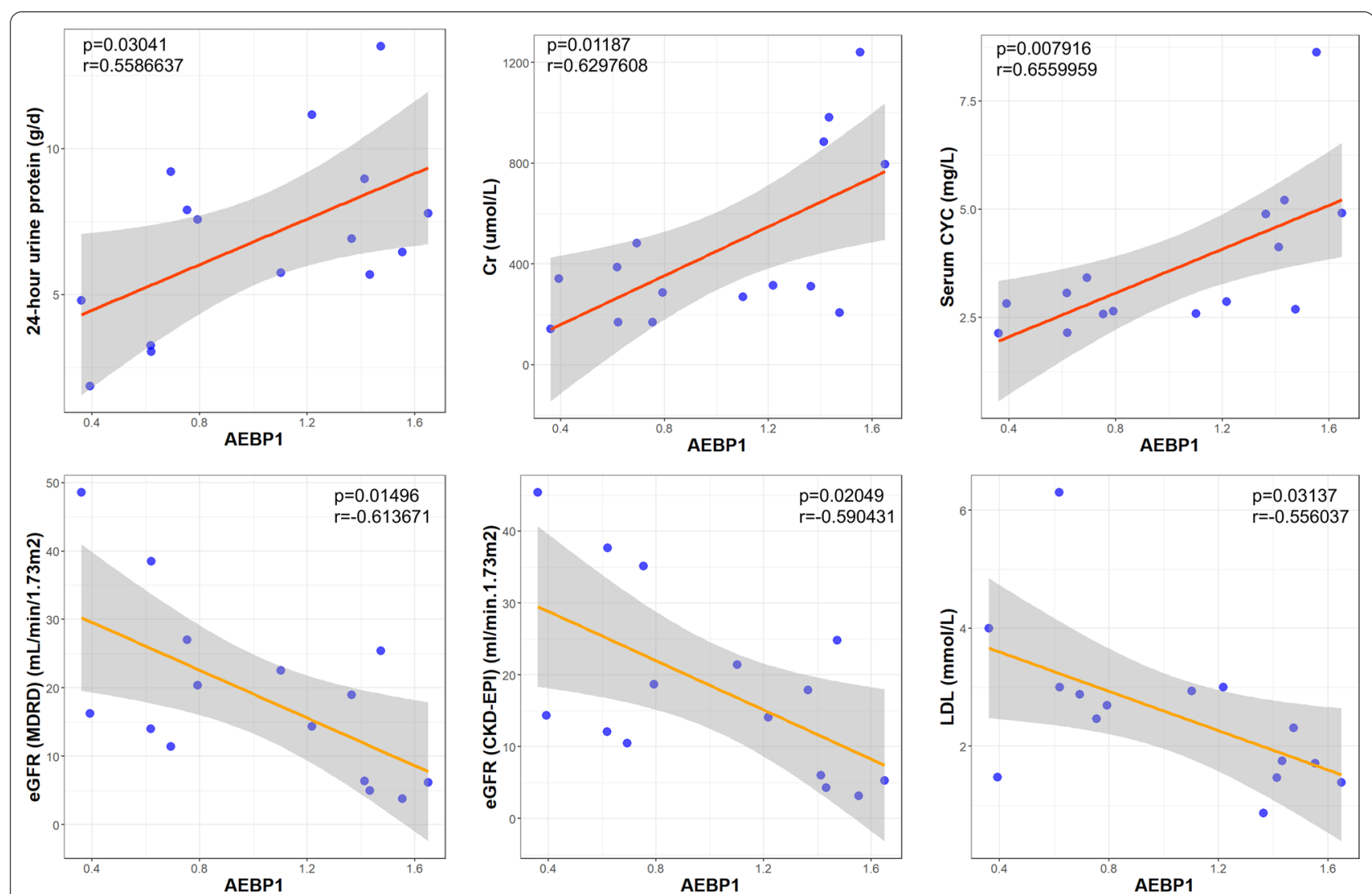

Fig. 6 Correlation analysis between the expression level of extracellular vesicle (EV) derived AEBP1 and the clinical parameters in DKD patients. Significant correlation could be found the expression level of AEBP1 and 24-h urine protein, Creatinine (Cr), serum cystatin-C (CYC), eGFR (MDRD), eGFR (CKD-EPI) and LDL

A

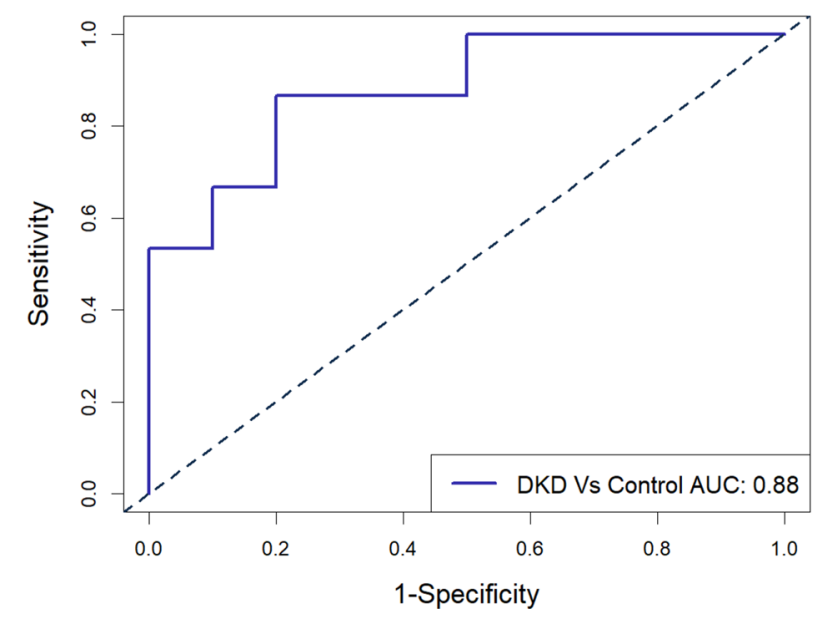

B

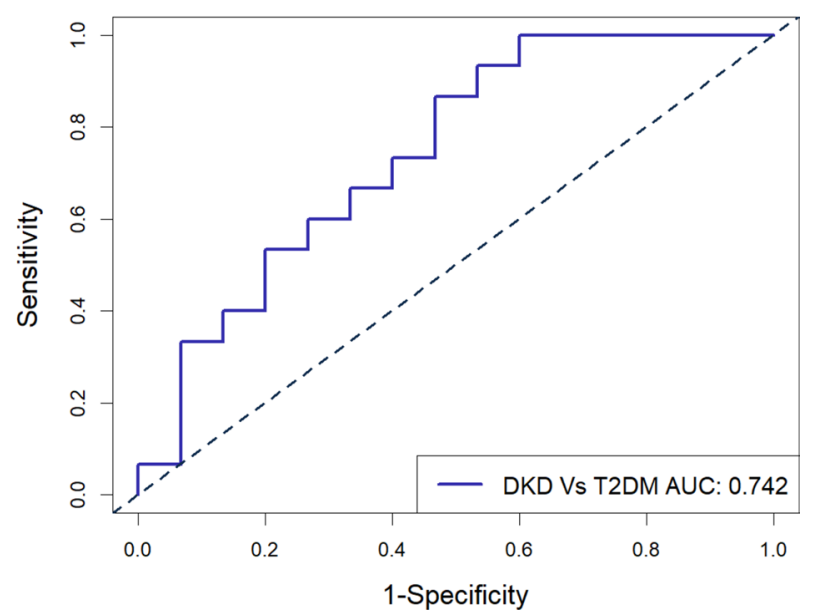

Fig. 7 Receiver operator characteristic (ROC) curve evaluation of the diagnostic accuracy of AEBP1 in differentiation of DKD patients, T2DM patients and healthy controls. A DKD and healthy controls, Area under curve (AUC) $=0.880, p<0.001$. B DKD and T2DM, Area under curve $(A \cup C)=0.742$, $p=0.009$ 
Table 4 Correlation between exosome AEBP1 level and clinical parameters in DKD patients

\begin{tabular}{|c|c|c|}
\hline \multirow[t]{2}{*}{ Clinical parameters } & \multicolumn{2}{|c|}{ Exosome AEBP1 level } \\
\hline & $\mathrm{R}$ value & $P$ value \\
\hline Age (yrs) & -0.283 & 0.307 \\
\hline BMI & -0.242 & 0.384 \\
\hline $\mathrm{SBP}(\mathrm{mmHg})$ & -0.309 & 0.263 \\
\hline $\mathrm{DBP}(\mathrm{mmHg})$ & -0.140 & 0.619 \\
\hline $\mathrm{HbA1c}(\%)$ & -0.062 & 0.827 \\
\hline eGFR (MDRD, $\mathrm{ml} / \mathrm{min} / 1.73 \mathrm{~m}^{2}$ ) & -0.614 & 0.0015 \\
\hline eGFR (CKD-EPI, ml/min/1.73m²) & -0.59 & 0.020 \\
\hline $\mathrm{BUN}(\mathrm{mmol} / \mathrm{L})$ & 0.298 & 0.280 \\
\hline Creatinine $(\mu \mathrm{mol} / \mathrm{L})$ & 0.629 & 0.012 \\
\hline $\mathrm{TC}(\mathrm{mmol} / \mathrm{L})$ & -0.170 & 0.545 \\
\hline TG (mmol) & -0.161 & 0.567 \\
\hline LDL (mmol/L) & -0.556 & 0.031 \\
\hline $\mathrm{HDL}(\mathrm{mmol} / \mathrm{L})$ & -0.034 & 0.905 \\
\hline 24-h urine protein (g/d) & 0.559 & 0.0304 \\
\hline Urine protein to creatinine ratio & -0.079 & 0.778 \\
\hline Albumin (g/L) & -0.335 & 0.222 \\
\hline Albumin/creatinine ratio $(\mathrm{mg} / \mathrm{g})$ & 0.258 & 0.374 \\
\hline Urine $\beta 2 M G$ (mg/L) & -0.003 & 0.993 \\
\hline Urine RBP (mg/L) & 0.357 & 0.255 \\
\hline Urine CYC (mg/L) & -0.189 & 0.667 \\
\hline Serum CYC (mg/L) & 0.656 & 0.008 \\
\hline Hemoglobin (g/L) & -0.424 & 0.116 \\
\hline WBC $\left(10^{9} / L\right)$ & -0.101 & 0.719 \\
\hline Monocytes $\left(10^{9} / \mathrm{L}\right)$ & -0.068 & 0.810 \\
\hline Lymphocytes $\left(10^{9} / \mathrm{L}\right)$ & -0.157 & 0.576 \\
\hline Neutrophils $\left(10^{9} / \mathrm{L}\right)$ & -0.041 & 0.885 \\
\hline hsCRP (mg/L) & 0.474 & 0.074 \\
\hline
\end{tabular}

Bold indicates $p<0.05$

$B M I$ body mass index, $S B P$ systolic blood pressure, $D B P$ diastolic blood pressure, T2DM type II diabetes mellitus, HbA1c glycated hemoglobin, MDRDThe Modification of Diet in Renal Disease, CKD-EPI The Chronic Kidney Disease Epidemiology Collaboration, $T C$ total cholesterol, $T G$ triglycerides, $H D L$ high density lipoprotein, $L D L$ low-density lipoprotein cholesterol, BUN blood urea nitrogen, RBP retinol-binding protein, $C Y C$ cystatin-C, WBC White Blood Cell

\section{Conclusions}

In conclusion, our results demonstrated that plasma EV-derived AEBP1 levels are capable of differentiating DKD patients from healthy controls and also exhibited good functions for indicating multiple critical clinical parameters. The plasma EV-derived AEBP1 level may serve as a novel and effective biomarker for DKD diagnosis.

\section{Supplementary Information}

The online version contains supplementary material available at https://doi. org/10.1186/s12967-021-03000-3.

Additional file 1: Table S1. Detailed information of the included microarray datasets. Table S2. Correlation coefficient and gene function of 15 intersected genes.

Additional file 2: Figure S1.

Additional file 3: Figure S2.

Additional file 4: Figure S3.

Acknowledgements

Not applicable.

\section{Authors' contributions}

YT, ZW, XS and LZ conceived and designed the experiments; $Y T, X W, Y L$ and ZW performed the experiments; $Y T, X W, Y L, Z W X S$ and $L Z$ analyzed the data; $J W$, JL, LS, GL, YH, SZ and FZ contributed reagents/materials/analysis tools; ZW, $X S$ and $L Z$ contributed to the writing of the manuscript. All authors read and approved the final manuscript.

\section{Funding}

This work was supported by National Natural Science Foundation of China [81600565 and 81700129], the Natural Science Foundation of Jiangsu Province for Distinguished Young Scholars [BK20190052], Translational Research Grant of NCRCH [2020WSA01], KJXW Scientific Grant from Suzhou Commission of Health for Young Scholars [KJXW2020002] and the Priority Academic Program Development of Jiangsu Higher Education Institutions (PAPD).

Availability of data and materials

All data generated or analysed during this study are included in this published article [and its additional files].

\section{Declarations}

\section{Ethics approval and consent to participate}

The present study was approved by the Ethical Committee of the First Affiliated Hospital of Soochow University and was carried out in accordance with the Declaration of Helsinki.

\section{Consent for publication}

Written informed consent was provided by all the included subjects.

\section{Competing interests}

The authors declare that they have no competing interests.

\section{Author details}

${ }^{1}$ Department of Nephrology, The First Affiliated Hospital of Soochow University, Suzhou 215006, China. ${ }^{2}$ Department of Gastroenterology, The First Affiliated Hospital of Soochow University, Suzhou 215006, China. ${ }^{3}$ MOE Engineering Center of Hematological Disease, Soochow University, Suzhou 215123,

China. ${ }^{4}$ Cyrus Tang Hematology Center, Soochow University, Suzhou 215123, China. ${ }^{5}$ National Clinical Research Center for Hematologic Diseases, The First 
Affiliated Hospital of Soochow University, Suzhou 215006, China. ${ }^{6}$ MOH Key Lab of Thrombosis and Hemostasis, Jiangsu Institute of Hematology, The First Affiliated Hospital of Soochow University, Suzhou 215006, China. ${ }^{7}$ Collaborative Innovation Center of Hematology, Soochow University, Suzhou 215006, China.

Received: 5 March 2021 Accepted: 23 July 2021

Published online: 31 July 2021

\section{References}

1. Anders H-J, Huber TB, Isermann B, Schiffer M. CKD in diabetes: diabetic kidney disease versus nondiabetic kidney disease. Nat Rev Nephrol. 2018;14:361-77.

2. Thomas MC, Brownlee M, Susztak K, Sharma K, Jandeleit-Dahm KA, Zoungas S, Rossing P, Groop P-H, Cooper ME. Diabetic kidney disease. Nat Rev Dis Primers. 2015;1:1-20.

3. Harjutsalo V, Groop P-H. Epidemiology and risk factors for diabetic kidney disease. Adv Chronic Kidney Dis. 2014;21:260-6.

4. Badal SS, Danesh FR. New insights into molecular mechanisms of diabetic kidney disease. Am J Kidney Dis. 2014;63:S63-83.

5. Khoury CC, Chen S, Ziyadeh FN: Pathophysiology of diabetic nephropathy. In: Chronic renal disease. Elsevier; 2020: 279-296

6. Toth-Manikowski S, Atta MG. Diabetic kidney disease: pathophysiology and therapeutic targets. J Diabetes Res. 2015. https://doi.org/10.1155/ 2015/697010.

7. Tong X, Yu Q, Ankawi G, Pang B, Yang B, Yang H. Insights into the role of renal biopsy in patients with T2DM: a literature review of global renal biopsy results. Diabetes Ther. 2020. https://doi.org/10.1007/ s13300-020-00888-w.

8. Maclsaac RJ, Ekinci El, Jerums G. Progressive diabetic nephropathy How useful is microalbuminuria?: contra. Kidney Int. 2014;86:50-7.

9. Coresh J, Heerspink HJ, Sang Y, Matsushita K, Arnlov J, Astor BC, Black C, Brunskill NJ, Carrero J-J, Feldman HI. Change in albuminuria and subsequent risk of end-stage kidney disease: an individual participantlevel consortium meta-analysis of observational studies. Lancet Diabetes Endocrinol. 2019;7:115-27.

10. Colombo M, Raposo G, Théry C. Biogenesis, secretion, and intercellular interactions of exosomes and other extracellular vesicles. Annu Rev Cell Dev Biol. 2014;30:255-89.

11. De Toro J, Herschlik L, Waldner C, Mongini C. Emerging roles of exosomes in normal and pathological conditions: new insights for diagnosis and therapeutic applications. Front Immunol. 2015;6:203.

12. Gangoda L, Boukouris S, Liem M, Kalra H, Mathivanan S. Extracellular vesicles including exosomes are mediators of signal transduction: are they protective or pathogenic? Proteomics. 2015;15:260-71.

13. Lee Y, El Andaloussi S, Wood MJ. Exosomes and microvesicles: extracellular vesicles for genetic information transfer and gene therapy. Hum Mol Genet. 2012:21:R125-34.

14. Xu W-C, Qian G, Liu A-Q, Li Y-Q, Zou H-Q. Urinary extracellular vesicle: a potential source of early diagnostic and therapeutic biomarker in diabetic kidney disease. Chin Med J. 2018;131:1357.

15. Sinha N, Kumar V, Puri V, Nada R, Rastogi A, Jha V, Puri S. Urinary exosomes: potential biomarkers for diabetic nephropathy. Nephrology. 2020. https://doi.org/10.1111/nep.13720.

16. Zhang W, Zhou X, Zhang H, Yao Q, Liu Y, Dong Z. Extracellular vesicles in diagnosis and therapy of kidney diseases. Am J Physiol Renal Physiol. 2016;311:F844-51.

17. National Kidney F. KDOQI Clinical practice guideline for diabetes and CKD: 2012 Update. Am J Kidney Dis. 2012;60:850-86.

18. Chinese Diabetes Society The consensus for prevention and treatment of diabetic kidney disease. Chin J Diabetes Mellitus 2014, 11:792.

19. American Diabetes A. Standards of medical care in diabetes-2010. Diabetes Care. 2010;33(Suppl 1):S11-61.

20. Gautier L, Cope L, Bolstad BM, Irizarry RA. affy-analysis of Affymetrix GeneChip data at the probe level. Bioinformatics. 2004;20:307-15.

21. Ritchie ME, Phipson B, Wu D, Hu Y, Law CW, Shi W, Smyth GK. limma powers differential expression analyses for RNA-sequencing and microarray studies. Nucleic Acids Res. 2015:43:e47.

22. Raivo K: pheatmap: Pretty Heatmaps. R package version 2015, 1.
23. Yu G, Wang LG, Han Y, He QY. clusterProfiler: an R package for comparing biological themes among gene clusters. OMICS. 2012;16:284-7.

24. Enderle D, Spiel A, Coticchia CM, Berghoff E, Mueller R, Schlumpberger M, Sprenger-Haussels M, Shaffer JM, Lader E, Skog J, Noerholm M. Characterization of RNA from Exosomes and Other Extracellular Vesicles Isolated by a Novel Spin Column-Based Method. PLoS ONE. 2015;10:e0136133.

25. Dong L, Lin W, Qi P, Xu MD, Wu X, Ni S, Huang D, Weng WW, Tan C, Sheng W, et al. Circulating long RNAs in serum extracellular vesicles: their characterization and potential application as biomarkers for diagnosis of colorectal cancer. Cancer Epidemiol Biomarkers Prev. 2016;25:1158-66.

26. Thongboonkerd $\mathrm{V}$. Roles for exosome in various kidney diseases and disorders. Front Pharmacol. 2019;10:1655.

27. Lu Y, Liu D, Feng Q, Liu Z. Diabetic nephropathy: perspective on extracellular vesicles. Front Immunol. 2020;1 1:943.

28. Jing H, Tang S, Lin S, Liao M, Chen H, Zhou J. The role of extracellular vesicles in renal fibrosis. Cell Death Dis. 2019;10:367.

29. Eissa S, Matboli M, Bekhet MM. Clinical verification of a novel urinary microRNA panal: 133b, -342 and -30 as biomarkers for diabetic nephropathy identified by bioinformatics analysis. Biomed Pharmacother. 2016:83:92-9.

30. Eissa S, Matboli M, Aboushahba R, Bekhet MM, Soliman Y. Urinary exosomal microRNA panel unravels novel biomarkers for diagnosis of type 2 diabetic kidney disease. J Diabetes Complications. 2016;30:1585-92.

31. Zubiri I, Posada-Ayala M, Sanz-Maroto A, Calvo E, Martin-Lorenzo M, Gonzalez-Calero L, de la Cuesta F, Lopez JA, Fernandez-Fernandez B, Ortiz A, et al. Diabetic nephropathy induces changes in the proteome of human urinary exosomes as revealed by label-free comparative analysis. $J$ Proteomics. 2014;96:92-102.

32. Rossi L, Nicoletti MC, Carmosino M, Mastrofrancesco L, Di Franco A, Indrio F, Lella R, Laviola L, Giorgino F, Svelto M, et al. Urinary excretion of kidney aquaporins as possible diagnostic biomarker of diabetic nephropathy. J Diabetes Res. 2017;2017:4360357.

33. Jager M, Lee MJ, Li C, Farmer SR, Fried SK, Layne MD. Aortic carboxypeptidase-like protein enhances adipose tissue stromal progenitor differentiation into myofibroblasts and is upregulated in fibrotic white adipose tissue. PLoS ONE. 2018;13:e0197777.

34. Kim SW, Muise AM, Lyons PJ, Ro HS. Regulation of adipogenesis by a transcriptional repressor that modulates MAPK activation. J Biol Chem. 2001;276:10199-206.

35. Majdalawieh A, Zhang L, Fuki IV, Rader DJ, Ro HS. Adipocyte enhancerbinding protein 1 is a potential novel atherogenic factor involved in macrophage cholesterol homeostasis and inflammation. Proc Natl Acad Sci U S A. 2006;103:2346-51.

36. Bogachev O, Majdalawieh A, Pan X, Zhang L, Ro HS. Adipocyte enhancerbinding protein 1 (AEBP1) (a novel macrophage proinflammatory mediator) overexpression promotes and ablation attenuates atherosclerosis in ApoE (-/-) and LDLR (-/-) mice. Mol Med. 2011;17:1056-64.

37. Ren J, Han Y, Ren T, Fang H, Xu X, Lun Y, Jiang H, Xin S, Zhang J. AEBP1 promotes the occurrence and development of abdominal aortic aneurysm by modulating inflammation via the NF-kappaB pathway. J Atheroscler Thromb. 2020;27:255-70

38. Holloway RW, Bogachev O, Bharadwaj AG, McCluskey GD, Majdalawieh $A F$, Zhang L, Ro HS. Stromal adipocyte enhancer-binding protein (AEBP1) promotes mammary epithelial cell hyperplasia via proinflammatory and hedgehog signaling. J Biol Chem. 2012;287:39171-81.

39. Gerhard GS, Hanson A, Wilhelmsen D, Piras IS, Still CD, Chu X, Petrick AT, DiStefano JK. AEBP1 expression increases with severity of fibrosis in NASH and is regulated by glucose, palmitate, and miR-372-3p. PLoS ONE. 2019;14:e0219764.

40. Shijo M, Honda H, Suzuki SO, Hamasaki H, Hokama M, Abolhassani N, Nakabeppu Y, Ninomiya T, Kitazono T, Iwaki T. Association of adipocyte enhancer-binding protein 1 with Alzheimer's disease pathology in human hippocampi. Brain Pathol. 2018;28:58-71.

41. Yorozu A, Yamamoto E, Niinuma T, Tsuyada A, Maruyama R, Kitajima H, Numata Y, Kai M, Sudo G, Kubo T, et al. Upregulation of adipocyte enhancer-binding protein 1 in endothelial cells promotes tumor angiogenesis in colorectal cancer. Cancer Sci. 2020;111:1631-44.

42. Hebebrand M, Vasileiou G, Krumbiegel M, Kraus C, Uebe S, Ekici AB, Thiel $\mathrm{CT}$, Reis A, Popp B. A biallelic truncating AEBP1 variant causes connective tissue disorder in two siblings. Am J Med Genet A. 2019;179:50-6. 
43. Hu W, Jin L, Jiang CC, Long GV, Scolyer RA, Wu Q, Zhang XD, Mei Y, Wu M. AEBP1 upregulation confers acquired resistance to BRAF (V600E) inhibition in melanoma. Cell Death Dis. 2013;4:e914.

44. Vatseba T, Sokolova L, Pushkarev V, Kovzun O, Guda B, Pushkarev V, Tronko M. Activation of the PI3K/Akt/mTOR/p70S6K1 signaling cascade in the mononuclear cells of peripheral blood: association with insulin and insulin-like growth factor levels in the blood of patients with cancer and diabetes. Cytol Genet. 2019;53:489-93.

45. Chittka D, Banas B, Lennartz L, Putz FJ, Eidenschink K, Beck S, Stempfl T, Moehle C, Reichelt-Wurm S, Banas MC. Long-term expression of glomerular genes in diabetic nephropathy. Nephrol Dial Transplant. 2018;33:1533-44.

46. Liang D, Liu S, Song Z, Liang W, Chang R, Li Y. Metformin ameliorates renal fibrosis in mice with unilateral ureteral obstruction and inhibits TGFB1-induced upregulation of cadherin-6 in renal proximal tubule epithelial cells. Am Diabetes Assoc 2018. https://doi.org/10.2337/db18-2199-PUB

47. Zhang H, Zhao T, Li Z, Yan M, Zhao H, Zhu B, Li P. Transcriptional profile of kidney from type 2 diabetic $\mathrm{db} / \mathrm{db}$ mice. J Diabetes Res. 2017;2017:8391253
48. Feng S-T, Gao Y-M, Yin D, Lv L-L, Wen Y, Li Z-L, Wang B, Wu M, Liu B-C. Identification of hub genes associated with accumulation of extracellular matrix as biomarkers of diabetic nephropathy. 2020.

49. Caza T, Hassen S, Dvanajscak Z, Kuperman M, Edmondson R, Herzog C, Storey A, Arthur J, Cossey LN, Sharma S, et al. NELL1 is a target antigen in malignancy-associated membranous nephropathy. Kidney Int. 2020. https://doi.org/10.1016/j.kint.2020.07.039.

50. Yokoi H, Kasahara M, Mori K, Ogawa Y, Kuwabara T, Imamaki H, Kawanishi T, Koga K, Ishii A, Kato Y, et al. Pleiotrophin triggers inflammation and increased peritoneal permeability leading to peritoneal fibrosis. Kidney Int. 2012;81:160-9.

51. Zhang $X$, Yang Y, Zhao Y. Macrophage phenotype and its relationship with renal function in human diabetic nephropathy. PLOS ONE. 2019:14:e0221991.

\section{Publisher's Note}

Springer Nature remains neutral with regard to jurisdictional claims in published maps and institutional affiliations.
Ready to submit your research? Choose BMC and benefit from:

- fast, convenient online submission

- thorough peer review by experienced researchers in your field

- rapid publication on acceptance

- support for research data, including large and complex data types

- gold Open Access which fosters wider collaboration and increased citations

- maximum visibility for your research: over $100 \mathrm{M}$ website views per year

At BMC, research is always in progress.

Learn more biomedcentral.com/submissions 